\title{
Muscle strength and executive function as complementary parameters for the assessment of impairment in Parkinson's disease
}

\author{
Força muscular e função executiva como parâmetros complementares para a \\ avaliação do comprometimento da doença de Parkinson \\ Dannyel Barbirato ${ }^{1,2}$, Alessandro Carvalho ${ }^{1,2,3}$, Narahyana Bom de Araujo 1,2, José Vicente Martins ${ }^{4}$, \\ Andrea Deslandes $1,2,5$
}

\begin{abstract}
Objective: To evaluate the relationship between the quantitative results of functional and cognitive performance of patients with Parkinson's disease (PD) and disease severity; and to study the relationship between patients' functional and cognitive capacity and motor impairment (Unified Parkinson's Disease Rating Scale - UPDRS III). Method: Twenty-nine subjects clinically diagnosed with PD were classified into three groups according to disease severity using the modified Hoehn and Yahr Scale (H\&Y). They were submitted to functional (Senior Fitness Test) and neuropsychological tests. Stepwise regression analysis showed a significant association between H\&Y and upper limb strength $\left(r^{2}=0.30 ; p=0.005\right)$ and executive function $\left(r^{2}=0.37 ; p=0.004\right)$. In relation to UPDRS III, there was a significant association between lower limb strength $\left(r^{2}=0.27 ; p=0.010\right)$ and global cognitive status $\left(r^{2}=0.24 ; p=0.024\right)$. Conclusion: The implementation of simple tests of functional capacity associated with neuropsychological testing can help to assess disease severity and motor impairment, and can be used to monitor the response to treatment in PD.
\end{abstract}

Keywords: Parkinson's disease, cognitive function, functional capacity, executive function, disease severity.

\section{RESUMO}

Objetivo: Avaliar a relação entre resultados quantitativos do desempenho funcional e cognitivo de pacientes com doença de Parkinson (DP) e a gravidade da doença; estudar a relação entre a capacidade funcional e cognitiva dos pacientes e o comprometimento motor (Unified Parkinson's Disease Rating Scale - UPDRS III). Método: Vinte e nove sujeitos diagnosticados clinicamente com DP foram classificados em três grupos de acordo com a gravidade da doença através da Escala de Hoehn \& Yahr (H\&Y) modificada, e submetidos a testes funcionais (Senior Fitness Test) e neuropsicológicos. As análises de regressão Stepwise mostraram associação significativa entre a gravidade da doença e a força de membros superiores $\left(r^{2}=0,30 ; p=0,005\right)$ e a função executiva $\left(r^{2}=0,37 ; p=0,004\right)$. Em relação ao comprometimento motor, houve associação significativa com a força de membros inferiores ( $\left.r^{2}=0,27 ; p=0,010\right)$ e com o estado cognitivo global $\left(r^{2}=0,24 ; p=0,024\right)$. Conclusão: Testes simples de capacidade funcional associados a testes neuropsicológicos podem contribuir para a avaliação da gravidade e do comprometimento motor e podem ser utilizados para o acompanhamento da resposta ao tratamento da DP.

Palavras-chave: doença de Parkinson, função cognitiva, capacidade funcional, função executiva, severidade da doença.

\footnotetext{
${ }^{1}$ Laboratório de Neurociência do Exercício, Universidade Gama Filho, Rio de Janeiro RJ, Brazil.

${ }^{2}$ Programa de Pós-Graduação em Psiquiatria e Saúde Mental, Universidade Federal do Rio de Janeiro, Rio de Janeiro RJ, Brazil.

${ }^{3}$ Centro de Estudo e Pesquisa do Envelhecimento, Instituto Vital Brazil, Rio de Janeiro RJ, Brazil.

${ }^{4}$ Instituto de Neurologia Deolindo Couto, Universidade Federal do Rio de Janeiro, Rio de Janeiro RJ, Brazil.

${ }^{5}$ Bolsista FAPERJ (Jovem Cientista do Nosso Estado), Rio de Janeiro RJ, Brazil.
}

Correspondence: Andrea Deslandes; Rua Sylvio da Rocha Pollis 300 / casa 02 / Barra da Tijuca; 22793-395 Rio de Janeiro RJ - Brasil;

E-mail:camazdeslandes@gmail.com

Conflict of interest: There is no conflict of interest to declare.

Support: Conselho Nacional de Pesquisa (CNPq, Brasil), Fundação de Amparo à Pesquisa do Estado do Rio de janeiro (FAPERJ) e Coordenação de Aperfeiçoamento de Pessoal de Nível Superior (CAPES), Rio de Janeiro, Brasil.

Received 20 November 2012; Received in final form 17 June 2013; Accepted 24 June 2013. 
Parkinson's disease (PD) is considered the second most prevalent neurodegenerative disease, with an estimated worldwide incidence of 160 cases per 100,000 population ${ }^{1}$, and can lead to a rapid decline in patients' physical and mental health ${ }^{2}$. Although usually classified as a movement-related disorder in terms of its cardinal signs (tremor, rigidity, bradykinesia and postural instability), PD should be considered a systemic disease, since Parkinsonians commonly manifest non-motor symptoms, such as sensory, autonomic, cognitive and behavioral changes ${ }^{3}$, prior to the motor alterations (preclinical phase) ${ }^{4}$.

The evaluation of impairment and disease progression is usually carried out using recognized and validated scales such as the UPDRS (Unified Parkinson's Disease Rating Scale) $)^{5,6}$ and the modified Hoehn and Yahr Scale (H\&Y) ${ }^{7}$. The domains assessed by these scales (motor and non-motor experiences relating to inactivities of daily living, motor examination and motor complications) show anatomicalclinical correlations between injured areas in the brain and symptoms relevant to each stage ${ }^{8}$. Monitoring these changes allows us to hypothesize a timeline of motor and nonmotor impairment evolution as the stages of PD advance ${ }^{9}$. The progression of PD is closely related to the loss of functional capacity, disability, the limitation in performing basic and instrumental daily living activities, and the impairment of mental health ${ }^{10}$. Although the disease progression can be viewed 'didactically' by the linear model suggested by Hawkes et al. ${ }^{9}$, in clinical practice a linear relationship does not necessarily exist between the onset of motor and non-motor signs and the Hoehn \& Yahr stages.

Although the UPDRS and Hoehn \& Yahr scales are indispensable for the recognition of the different stages of the disease, it is necessary to further complement the clinical evaluation using rating scales and quantitative instruments that measure functional capacity and non-motor symptoms. The new version of the UPDRS ${ }^{11}$ includes an evaluation of non-motor experiences in daily activities; however, there are still gaps to be filled in order to recognize specific aspects of the cognitive and functional capacity of Parkinsonians. Some studies have adopted neuropsychological tests in PD patients to cover a greater number of fields related to mental health. Likewise, the use of the Senior Fitness Test (SFT) to quantitatively assess functional capacity has recently been tested and correlated moderately with the UPDRS ${ }^{12}$.

We hypothesized that the evaluation of functional and cognitive capacity may contribute to monitoring treatment progress in PD. Therefore, the aim of our study was to evaluate the relationship between the cognitive and functional performance of patients with PD and their disease severity $(\mathrm{H} \& \mathrm{Y})$. In addition, we evaluated the relationship between patients' functional and cognitive capacity and their motor impairment (UPDRS III).

\section{METHOD}

\section{Subjects}

Twenty-nine subjects who had been clinically diagnosed with PD by neurologists according to the UK Parkinson's Disease Society Brain Bank clinical diagnostic criteria ${ }^{13}$ at the Institute of Neurology Deolindo Couto (INDC) of the Federal University of Rio de Janeiro (UFRJ), participated in this study To evaluate variables such as behavior, activities of daily living (ADL), motor function and disease severity in PD patients, the UPDRS ${ }^{5,6}$ and the modified Hoehn and Yahr Scale 7 were used. The subjects were classified into three groups according to disease severity: group 1 (H\&Y stage 1 and 1.5, mild, with unilateral involvement), group 2 (H\&Y stage 2 and 2.5, moderate, with bilateral involvement and no impairment of balance) and group 3 (H\&Y stage 3, moderate, with bilateral involvement and balance impairment). The Mini Mental State Examination (MMSE) ${ }^{14}$ was applied to assess the subjects' global cognitive status, and depressive symptoms were assessed using the Hamilton Depression Rating Scale (HAM-D) ${ }^{15}$. Inclusion criteria were: age between 45 and 80 years, a diagnosis of PD, and stage $1-3$ on the $H \& Y$ scale $^{7}$. Exclusion criteria included any disease that hindered the application of an evaluation instrument, previous cerebral infarction or other mental comorbidities, the use of treatment such as psychotherapy, and illiteracy. All subjects gave informed consent and the study was approved by the Ethics Committee of the INDC (protocol number 008-09-CEP).

\section{Functional capacity evaluation}

To assess functional capacity, the following tests (from the Senior Fitness Test) ${ }^{16}$ were used: Chair Stand Test (lower limb strength), Arm Curl Test (upper limb strength), 2-Minute Step Test (lower limb endurance), Chair Sit and Reach Test (lower limb flexibility), Back Scratch Test (upper limb flexibility), and 8-Foot Up and Go Test (agility and dynamic balance). Besides these, we also used the 10-Meter Walk Test (walking speed) ${ }^{17}$, Timed Up and Go (TUG) Test modified ${ }^{18}$, Functional Reach (dynamic balance and fall risk) ${ }^{19}$ and Berg Balance Scale (functional balance and fall risk) ${ }^{20}$. All of these tests have good reliability and validity values ${ }^{16}$.

\section{Neuropsychological evaluation}

To assess the neuropsychological aspects of PD, the following evaluation tools were used: Trail Making Test (TMT) A and B (executive function) ${ }^{21}$, Stroop Test (attention and inhibitory control) ${ }^{21}$, Verbal Fluency Test (animal categoryword production and semantic memory) ${ }^{22}$, Rey-Osterrieth Complex Figure Test (ROCF) immediate and delayed recall conditions (visuospatial ability and visuospatial memory) ${ }^{23}$, and subtests of the revised Wechsler Adult Intelligence Scale (WAIS-R) ${ }^{24}$ [Forward and Backward Digit Span Test (working memory), Digit Symbol Test (processing speed) and 
Similarities (verbal comprehension and abstract reasoning)]. We used validated Portuguese versions of the tests.

\section{Statistical analysis}

To test for the normality and homoscedasticity of data, the Shapiro-Wilk and Levene's tests were applied, respectively. To compare the three groups we used one-way ANOVA for parametric data and a Kruskall-Wallis one-way ANOVA for nonparametric data, with a Tukey post hoc test. In addition, a stepwise regression analysis was performed to determine cognitive and functional variables that were best related to motor impairment (UPDRS III) and disease severity (H\&Y). Data analysis was performed using SPSS software version 19. (New York, EUA) A significance level of $p \leq 0.05$ indicated statistical significance.

\section{RESULTS}

Sample characteristics are described in detail in Table 1. There was no statistically significant difference between age, weight, height, education, duration of disease, comorbidities, number of medications, MMSE or HAM-D. As expected, there was a significant difference in UPDRS III between groups (Table 1), and the post hoc test showed that there was a difference between group 1 (stage 1-1.5) and group 3 (stage 3) ( $\mathrm{p}=0.007)$. Regarding functional capacity, patients in group 1 (stage $1-1.5$ ) showed better performance in upper limb strength than those in group 3 (stage 3$)(p=0.037)$ (Table 2). In terms of cognitive domains, a significant difference was found in the Verbal Fluency Test (Table 3). The post hoc test showed that there was a difference between group 3 (stage 3 ) and groups 1 (stage 1-1.5) $(\mathrm{p}=0.011)$ and 2 (stage 2-2.5) $(\mathrm{p}=0.029)$. Moreover, there was a significant difference in the delayed recall condition of the Rey Complex Figure Test between group
1 (stage $1-1.5)$ vs group 2 (stage $2-2.5)(\mathrm{p}=0.027)$ and 3 (stage 3) $(\mathrm{p}=0.008)$ (Table 3).

Finally, the stepwise regression analysis showed an association between the delayed recall of complex figures and upper limb strength with disease severity (H\&Y). Motor impairment (UPDRS III) was associated with lower limb strength and global cognitive status (MMSE) (Figure 1).

\section{DISCUSSION}

The present study aimed to evaluate the relationship between the cognitive and functional quantitative performance of PD patients and disease severity, as well as the relationship between motor impairment (UPDRS III) and patients' cognitive and functional capacity. Based on normative data from healthy elderly ${ }^{25}$, we found that the fitness level of our sample was below the expected level of fitness in both upper $(73 \%)$ and lower (82\%) body strength.

Using a regression model, we found an association between disease severity $(\mathrm{H} \& \mathrm{Y})$ and upper limb strength that correlated with the level of disease severity in 30\% of our sample, showing that simple tests of upper limb strength can contribute to the evaluation of PD staging. In addition, the delayed recall condition of the Rey Complex Figure Test correlated with the level of disease severity in $37 \%$, indicating that visuospatial memory is directly related to the worsening of PD. In terms of motor impairment (UPDRS III), there was an association with both lower limb strength and global cognitive status-correlating with the level of impairment in $27 \%$ and $24 \%$, respectively-showing that both functional capacity and cognitive function influence the motor performance of PD patients. As expected, significant differences were found between the UPDRS motor scores of group 1 (stage 1-1.5) and group 3 (stage 3) patients. However, no significant differences were found between group 2 (stage 2-2.5)

Table 1. Sample analysis.

\begin{tabular}{|c|c|c|c|c|c|}
\hline & Group 1 & Group 2 & Group 3 & & \\
\hline & $\mathrm{H} \& \mathrm{Y}(1-1.5)$ & $\mathrm{H} \& \mathrm{Y}(2-2.5)$ & $\mathrm{H} \& \mathrm{Y}(3)$ & $\mathrm{F}$ & $\mathrm{p}$ \\
\hline & $\mathrm{n}=6(4 \mathrm{M} / 2 \mathrm{~F})$ & $\mathrm{n}=17(14 \mathrm{M} / 3 \mathrm{~F})$ & $n=6(3 M / 3 F)$ & & \\
\hline Age (years)a & $59.50(58.00-66.50)$ & $63.00(53.50-72.50)$ & $64.00(58.75-77.00)$ & 0.968 & 0.616 \\
\hline Weight (kg) & $72.81 \pm 19.12$ & $69.81 \pm 15.87$ & $65.17 \pm 10.25$ & 0.367 & 0.696 \\
\hline Height (cm) & $168.33 \pm 9.14$ & $167.00 \pm 8.91$ & $161.33 \pm 5.81$ & 1.261 & 0.301 \\
\hline Education (years) & $7.50(6.25-9.75)$ & $8.50(5.00-15.75)$ & $6.00(5.00-9.50)$ & 0.875 & 0.689 \\
\hline Duration of disease (years) & $6.33 \pm 3.67$ & $5.65 \pm 2.52$ & $6.00 \pm 2.28$ & 0.149 & 0.863 \\
\hline Comorbidities $\left(n^{\circ}\right)^{a}$ & $1.50(1.00-2.00)$ & $1.00(0.50-2.00)$ & $1.00(0.75-2.00)$ & 0.773 & 0.680 \\
\hline Medications $\left(n^{0}\right)^{a}$ & $2.50(1.75-3.25)$ & $2.00(2.00-3.00)$ & $3.00(2.00-3.25)$ & 0.674 & 0.714 \\
\hline UPDRS III motor (score) & $24.83 \pm 9.20^{b}$ & $35.71 \pm 10.10$ & $43.17 \pm 7.47^{b}$ & 5.727 & $0.009^{\circ}$ \\
\hline MMSE (score) & $28.00(27.75-29.25)$ & $26.00(24.00-28.50)$ & $23.00(20.75-27.50)$ & 5.839 & 0.054 \\
\hline Hamilton (score) & $3.67 \pm 2.16$ & $6.94 \pm 4.34$ & $7.50 \pm 4.72$ & 1.702 & 0.202 \\
\hline
\end{tabular}

a $X^{2}$ Kruskal-Wallis one-way ANOVA. Data are expressed as mean \pm standard deviation for parametric data and median (interquartile intervals $25-75 \%$ ) for non-parametric data; ${ }^{\circ}$ Difference between groups 1 and $3 ;{ }^{\circ} p<0.05$.

F: female; HY: Hoehn and Yahr scale; M: male; MMSE: Mini Mental State Examination; UPDRSIII: Unified Parkinson's Disease Rating Scale. 
Table 2. Functional capacity of patients with Parkinson's disease according to disease severity.

\begin{tabular}{|c|c|c|c|c|c|}
\hline \multirow{3}{*}{ Functional capacity } & Group 1 & Group 2 & Group 3 & \multirow{3}{*}{$\mathrm{F}$} & \multirow{3}{*}{$\mathrm{P}$} \\
\hline & $H \& Y(1-1.5)$ & $H \& Y(2-2.5)$ & $H \& Y(3)$ & & \\
\hline & $n=6(4 M / 2 F)$ & $n=17(14 M / 3 F)$ & $n=6(3 M / 3 F)$ & & \\
\hline Berg Balance Scale (points) & $53.33 \pm 2.80$ & $51.88 \pm 3.50$ & $50.50 \pm 5.28$ & 0.836 & 0.445 \\
\hline Functional Reach (cm) & $25.88 \pm 8.99$ & $24.13 \pm 6.89$ & $28.23 \pm 10.57$ & 0.578 & 0.568 \\
\hline 8-Foot UP and Go Test (seconds)a & $8.22(7.95-10.35)$ & $9.87(8.47-11.31)$ & $11.54(7.78-15.16)$ & 1.917 & 0.383 \\
\hline TUG modified (seconds) & $10.43 \pm 1.78$ & $14.31 \pm 6.01$ & $14.14 \pm 4.17$ & 1.337 & 0.280 \\
\hline 10 Meter Walk Test (seconds)a & $7.52(5.80-8.57)$ & $7.21(5.89-8.12)$ & $9.85(6.67-13.15)$ & 2.048 & 0.359 \\
\hline 2-Minute Step Test (repetitions)a & $63.50(49.00-77.75)$ & $54.00(39.50-78.00)$ & $30.00(22.50-53.50)$ & 3.479 & 0.176 \\
\hline Arm Curl Test (repetitions) & $17.17 \pm 3.76^{b}$ & $14.41 \pm 4.15$ & $11.17 \pm 3.54^{\mathrm{b}}$ & 3.440 & $0.047^{\circ}$ \\
\hline Chair Stand Test (repetitions) & $12.60 \pm 4.04$ & $10.71 \pm 3.37$ & $8.67 \pm 2.07$ & 1.987 & 0.158 \\
\hline Back Scratch Test (cm) & $-19.50 \pm 14.72$ & $-25.85 \pm 12.48$ & $-24.75 \pm 13.73$ & 0.519 & 0.601 \\
\hline Chair Sit and Reach Test $(\mathrm{cm})^{a}$ & $-16.00(0.00-21.25)$ & $0.00(0.00-(-16.50))$ & $-9.50(-3.75-(-15.88))$ & 2.158 & 0.340 \\
\hline
\end{tabular}

${ }^{a} X^{2}$ Kruskal-Wallis one-way ANOVA. Data are expressed as mean \pm standard deviation for parametric data and median (interquartile intervals $\left.25-75 \%\right)$ for non-parametric data; ${ }^{b}$ Difference between groups 1 and $3 ;^{\circ} p \leq 0.05$.

F: female; HY: Hoehn and Yahr scale; M: male.

Table 3. Cognitive function of patients with Parkinson's disease according to disease severity.

\begin{tabular}{|c|c|c|c|c|c|}
\hline \multirow{3}{*}{ Cognitive aspects } & Group 1 & Group 2 & Group 3 & \multirow{3}{*}{$\mathrm{F}$} & \multirow{3}{*}{$\mathrm{P}$} \\
\hline & $\mathrm{H} \& \mathrm{Y}(1-1.5)$ & $\mathrm{H} \& \mathrm{Y}(2-2.5)$ & $\mathrm{H} \& \mathrm{Y}(3)$ & & \\
\hline & $\mathrm{n}=6(4 \mathrm{M} / 2 \mathrm{~F})$ & $\mathrm{n}=17(14 \mathrm{M} / 3 \mathrm{~F})$ & $n=6(3 M / 3 F)$ & & \\
\hline TMTA (seconds)a & $44.00(35.75-64.00)$ & $82.00(38.00-103.00)$ & $99.00(54.00-129.25)$ & 2.754 & 0.252 \\
\hline TMT B (seconds) & $118.50 \pm 48.89$ & $184.64 \pm 135.79$ & $147.80 \pm 106.53$ & 0.723 & 0.496 \\
\hline Stroop Core Test (seconds)a & $25.00(17.75-28.50)$ & $30.50(24.25-34.00)$ & $34.50(26.00-65.00)$ & 4.517 & 0.104 \\
\hline Digit Foward Test (score) & $5.83 \pm 1.47$ & $5.35 \pm 1.97$ & $4.33 \pm 1.75$ & 1.072 & 0.357 \\
\hline Digit Backward Test (score)a & $5.00(3.75-6.00)$ & $5.00(3.50-6.00)$ & $2.50(2.00-4.25)$ & 5.177 & 0.075 \\
\hline Digit Symbol Test (score) & $24.00 \pm 10.14$ & $17.75 \pm 10.87$ & $12.17 \pm 9.83$ & 1.899 & 0.171 \\
\hline Similarities (score) & $16.00 \pm 2.97$ & $16.41 \pm 5.44$ & $13.83 \pm 5.04$ & 0.601 & 0.556 \\
\hline Verbal Fluency Test (score) & $21.17 \pm 5.00$ & $18.82 \pm 3.84$ & $13.00 \pm 5.66^{b}$ & 5.521 & $0.010 *$ \\
\hline Rey Figure (score) ${ }^{a}$ & $33.00(30.75-34.00)$ & $29.00(17.25-33.75)$ & $22.00(12.50-31.00)$ & 4.694 & 0.096 \\
\hline Rey Figure delayed recall (score) & $19.17 \pm 9.28^{\circ}$ & $9.46 \pm 6.59$ & $5.00 \pm 4.47$ & 6.215 & $0.008^{d}$ \\
\hline
\end{tabular}

${ }^{2} X^{2}$ Kruskal-Wallis one-way ANOVA. Data are expressed as mean \pm standard deviation for parametric data and median (interquartile intervals $25-75 \%$ ) for non-parametric data; ${ }^{\mathrm{b}}$ Difference between group 3 vs groups 1 and $2 ;^{\circ}$ Difference between group 1 vs groups 2 and $3 ;{ }^{d *} p \leq 0.05$.

$\mathrm{A}$ and B:executive function; F: female; HY: Hoehn and Yahr scale; M: male; TMT:Trail Making Test.

patients and the other two groups; the same was true for the upper limb strength test. These results show that the UPDRS motor examination seems to be more sensitive to changes in the early and moderate stages of PD [group 1 (stage 1-1.5) and 3 (stage 3)], but is inadequate for distinguishing intermediate stages [group 2 (stage 2-2.5)].

Regarding cognition, the present study found that verbal fluency performance is directly related to disease severity. This result was also found in another study from our laboratory ${ }^{26}$. Similar neuropsychological findings suggest that cognitive deficits in PD are reflected by instruments that evaluate executive functioning ${ }^{27,28}$, as in the Verbal Fluency Test. These cognitive deficits worsen in the later stages of $\mathrm{PD}^{29}$. It was also found that the delayed recall of complex figures was related to disease severity (H\&Y), i.e., the more severe the disease, the greater the deficit in visuospatial memory. Deficits in visuospatial functions ${ }^{28}$ and visual memory in PD have been reported elsewhere ${ }^{30}$. Specifically, visual memory impairments have been observed only in the later stages of the disease ${ }^{30}$. These neuropsychological deficits can be explained by changes in the patients' dorsolateral prefrontal area ${ }^{30,31}$.

Little is known about the correlation between disease stage assessed qualitatively through the UPDRS and $\mathrm{H} \& \mathrm{Y}$, and quantitative functional tests (such as the Senior Fitness Test battery), making it difficult to contextualize our results. Cancela et al. ${ }^{12}$ correlated the SFT with the total UPDRS $\left(\mathrm{r}_{\mathrm{s}}=0.70 ; \mathrm{p}<0.01\right)$ and the UPDRS motor examination $\left(\mathrm{r}_{\mathrm{s}}=0.661 ; \mathrm{p}<0.01\right)$. Our study showed that the SFT can be safely applied to PD patients between stages 1 and 3 of the H\&Y scale, which is in agreement with Cancela et al. ${ }^{12}$. In another study, Barbieri et al. ${ }^{32}$ found a correlation between endurance, strength, coordination, balance and agility tests with the UPDRS motor examination. However, when separated into groups (unilateral or bilateral compromise), a correlation was found only between the upper limb strength 

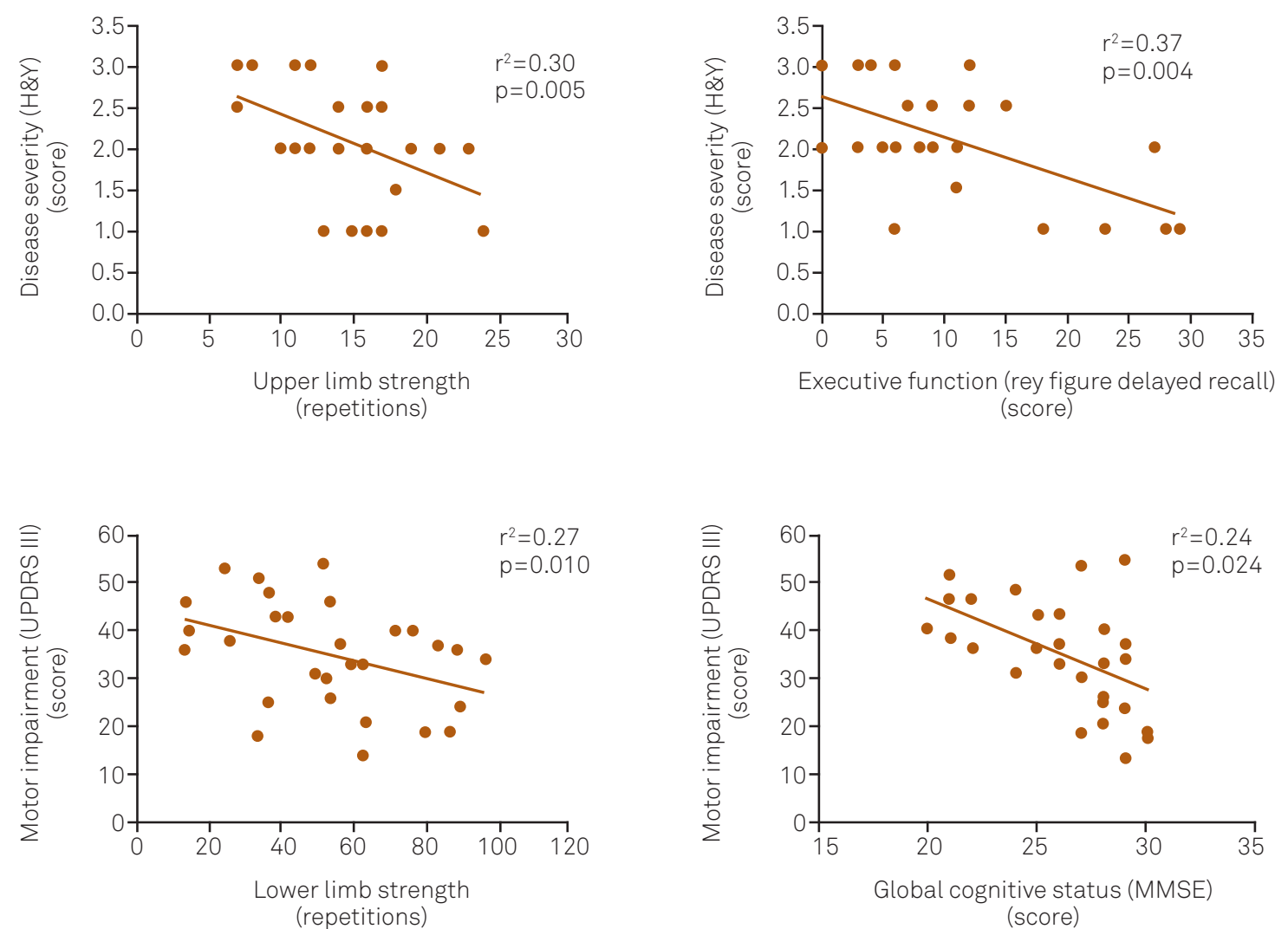

Figure 1. Relationship between disease severity (H\&Y) and motor impairment (UPDRS III) with the functional and cognitive capacity. UPDRS III: Unified Parkinson's Disease Rating Scale; H\&Y: Hoehn and Yahr.

test and the UPDRS motor examination for both groups $(\mathrm{r}=-0.34$ / $\mathrm{r}=-0.53)$; no correlation was found between functional tests and disease severity. Our findings corroborate these authors' findings with regard to the association between the UPDRS motor domains and functional tests. However, we also found an association between upper limb strength and disease severity (H\&Y).

The loss of functional independence compromises the performance of $\mathrm{ADL}$, and therefore is a main target in rehabilitation treatments. A thorough evaluation of the level of physical and mental impairments in PD patients is necessary to foster strategies for disease treatment, and provide assistance based on the specific needs of each patient. From this viewpoint, our hypothesis presents a global evaluation model for PD patients, which adds simple and well-validated tests. Our hypothesis has yet to be confirmed through the application of this model to a broader population and over time. Despite the non-motor and motor changes that are known and expected with the development of PD, this study shows the importance of evaluating specific aspects of functional capacity and cognitive function. Upper and lower body strength and executive function influence the severity of disease, and should be used by both researchers and clinicians.

Normally, the executive dysfunction in PD progresses to corresponding motor deficits ${ }^{33}$. Thus, the assessment of executive functions is suitable not only for assessing executive functioning, which is the primary cognitive deficit in $\mathrm{PD}$, but also as a complementary measure of motor changes. Furthermore, as executive functions are related to cognitive flexibility, planning and self-regulation of mental processes and behavior (behavioral adaptation ${ }^{34}$, a more complete assessment of the functionality of the PD patients needs to take into account the essential skills needed to perform ADL and independent living, an examination of the executive functions, and a physical examination.

There seems to be a relationship between the reduction in physical function and the increased risk of mortality in PD patients ${ }^{35}$. In this context, the assessment of functional capacity in PD has been increasingly reported in the literature ${ }^{12,32,35,36}$, highlighting a sensitive measure that could be used as a possible predictor for the evolution of the disease. These findings justify the inclusion of functional capacity tests (e.g., upper and lower limb strength) in the clinical evaluation of PD patients on account of their direct relationship with disability, risk of falls, quality of life, worsening mobility and increased mortality in PD.

This is the first study to propose a quantitative and more comprehensive assessment of physical and mental health in PD patients, combining traditional instruments such as the UPDRS and the H\&Y scale and supplemented by functional 
capacity tests and neuropsychological evaluation. The methodology proposed in this study corroborates the view that Parkinson's disease should be recognized and treated as a systemic disease.

Our study has major limitations, such as a small sample size, use of the modified version of the H\&Y scale, and a cross-sectional analysis. Although the Senior Fitness Test has normative scores, there is no normative database for the Brazilian population. Future studies that compare normative scores and different diseases (e.g., Alzheimer's, Parkinson's) could further expand this area of research.
We conclude that upper limb strength and executive function are best associated with PD severity. In addition, lower limb strength and global cognitive status (MMSE) are best related to motor impairment. Functional and neuropsychological tests can be used to complement specific PD assessments and evaluate the physical and mental health of PD patients, as well as to monitor the response to the treatment of PD by quantitative parameters. Further studies should be conducted in order to verify whether or not these associations are maintained throughout the course of the disease.

\section{References}

1. World Health Organization. Atlas: country resources for neurological disorders 2004: results of a collaborative study of the World Health Organization. Geneva, 2004

2. Pohar SL, Allyson Jones C. The burden of Parkinson's disease and concomitant comorbidities. Arch Gerontol Geriatr 2009;49:317-321.

3. Pandya M, Kubu C, Giroux M. Parkinson disease: not just a movement disorder. Cleve Clin J Med 2008;75:856-864

4. Tolosa E, Compta Y, Gaig C. The premotor phase of Parkinson's disease. Parkinsonism Relat Disord 2007;13(Suppl):S2-S7.

5. Fahn S, Elton R. Members of the UPDRS Development Committee. The Unified Parkinson's Disease Rating Scale. In: Fahn S, Marsden CD, Calne DB, Goldstein M (eds). Recent Developments in Parkinson's Disease, Vol. 2. 1987:153-163. Florham Park, NJ: Mcmellam Health Care Information.

6. Movement Disorder Society Task Force on Rating Scales for Parkinson's Disease. The Unified Parkinson's Disease Rating Scale (UPDRS): status and recommendations. Mov Disord 2003;18:738-750.

7. Goetz CG, Poewe W, Rascol O, et al. Movement Disorder Society Task Force report on the Hoehn and Yahr staging scale: status and recommendations. Mov Disord 2004;19:1020-1028.

8. Braak H, Del Tredici K, Rüb U, de Vos R, Jansen Steur E, Braak E. Staging of brain pathology related to sporadic Parkinson's disease. Neurobiol Aging 2003;24:197-211.

9. Hawkes CH, Del Tredici K, Braak H. A timeline for Parkinson's disease. Parkinsonism Relat Disord 2010;16:79-84.

10. Dibble LE, Cavanaugh JT, Earhart GM, Ellis TD, Ford MP, Foreman KB. Charting the progression of disability in Parkinson disease: study protocol for a prospective longitudinal cohort study. BMC Neurol 2010;10:110

11. Goetz CG, Tilley BC, Shaftman SR, et al. Movement Disorder Societysponsored revision of the Unified Parkinson's Disease Rating Scale (MDS-UPDRS): scale presentation and clinimetric testing results. Mov Disord 2008;23:2129-2170.

12. Cancela JM, Ayan C, Gutierrez-Santiago A, Prieto I, Varela S. The senior fitness test as a functional measure in Parkinson's disease: a pilot study. Parkinsonism Relat Disord 2012;18:170-173.

13. Hughes AJ, Daniel SE, Kilford L, Lees AJ. Accuracy of clinical diagnosis of idiopathic Parkinson's disease: a clinicopathological study of 100 cases. J Neurol Neurosurg Psychiatry 1992;55:181-184.

14. Bertolucci PHF, Brucki SMD, Campacci SR, Juliano Y. The Mini-Mental State Examination in an outpatient population: influence of literacy. Arq Neuropsiquiatr 1994;52:1-7.

15. Moreno RA, Moreno DH. Hamilton and Montgomery \& Asberg Depression Rating Scales. Rev Psiq Clín 1998;25:1-17.
16. Rikli ER, Jones CJ. Development and validation of a functional fitness test for community-residing older adults. J Aging Phys Act 1999;7:129-161.

17. Wade DT. Measurement in Neurological Rehabilitation. 1992:1-388 Oxford: Oxford University Press.

18. Shumway-Cook A, Brauer S, Woollacott M. Predicting the probability for falls in community-dwelling older adults using the Timed Up \& Go Test. Phys Ther 2000;80:896-903.

19. Duncan PW, Weiner DK, Chandler J, Studenski S. Functional reach: a new clinical measure of balance. J Gerontol 1990;45:192-197.

20. Miyamoto ST, Lombardi Junior I, Berg KO, Ramos LR, Natour J. Brazilian version of the Berg balance scale. Braz J Med Biol Res 2004;37:1411-1421.

21. Strauss E, Sherman EMS, Spreen O. A Compendium of Neuropsychological Tests: Administration, Norms, and Commentary. 2006:1-1204. Oxford: Oxford University Press.

22. Brucki SMD, Malheiros SMF, Okamoto IH, Bertolucci PHF. Normative data for the animals category verbal fluency test in our environment. Arq Neuropsiquiatr 1997;55:56-61.

23. Oliveira M, Rigoni M, Andretta I, Moraes JF. Rey Complex Figure validation for the brazilian population. Aval Psicol 2004;3:33-38.

24. Wechsler D. Wechsler Adult Intelligence Scale-Revised manual (WAIS-R). 1981:1-156. New York, USA: The Psychological Corporation.

25. Rikli R, Jones C. Functional fitness normative scores for communityresiding older adults, ages 60-94.J Aging Phys Act 1999;7:162-181.

26. Araujo NB, Barca ML, Engedal K, Coutinho ES, Deslandes AC, Laks J. Verbal fluency in Alzheimer's disease, Parkinson's disease, and major depression. Clinics (Sao Paulo) 2011;66:623-627.

27. Piovezan M, Teive H, Piovesan E, Mader M, Werneck L. Cognitive function assessment in idiopathic Parkinson's disease. Arq Neuropsiquiatr 2007;65:942-946.

28. Verbaan D, Marinus J, Visser M, et al. Cognitive impairment in Parkinson's disease.J Neurol Neurosurg Psychiatry 2007;78:1182-1187.

29. Riedel O, Klotsche J, Spottke A, et al. Cognitive impairment in 873 patients with idiopathic Parkinson's disease. Results from the German Study on Epidemiology of Parkinson's Disease with Dementia (GEPAD). J Neurol 2008;255:255-264.

30. Vera-Cuesta H, Vera-Acosta H, Alvarez-Gonzalez L, FernandezMaderos I, Casabona-Fernandez E. Frontal dysfunction in idiopathic Parkinson's disease. Rev Neurol 2006;42:76-84.

31. Zgaljardic D, Borod J, Foldi N, Mattis P. A review of the cognitive and behavioral sequelae of Parkinson's disease: relationship to frontostriatal circuitry. Cogn Behav Neurol 2003;16:193-210. 
32. Barbieri FA, Rinaldi NM, Santos PC, et al. Functional capacity of Brazilian patients with Parkinson's disease (PD): Relationship between clinical characteristics and disease severity. Arch Gerontol Geriatr 2012;54:83-88.

33. Ostrosky-Solís F. Neuropsychological characteristics of parkinson's disease. Rev Neurol 2000;30:788-796.

34. Oliveira-Souza R, Moll J, Ignácio FA, Tovar-Moll F. Cognition and executive functions. In: Lent, R (ed). Neuroscience of Mind and Behavior. 2008; pp. 287-307. Rio de Janeiro: Guanabara Koogan.
35. Gray W, Hildreth A, Bilclough J, Wood B, Baker K, Walker R. Physical assessment as a predictor of mortality in people with Parkinson's disease: a study over 7 years. Mov Disord 2009;24:1934-1940.

36. Paul SS, Canning CG, Sherrington C, Lord SR, Close JC, Fung VS. Three simple clinical tests to accurately predict falls in people with Parkinson's disease. Mov Disord 2013;28:655-662. 